\title{
PRIVATE SURGEONS' ATTITUDE TOWARDS INFORMED CONSENT, KUWAIT
}

\author{
Saadoun Faris Al Azmi ${ }^{1}$, Bashair Abdullah Almutairi ${ }^{2}$ \\ ${ }^{1-2}$ Department of Medical Records, College of Health Sciences, Public Authority of Applied \\ Education and Training (PAAET), Kuwait
}

\section{ABSTRACT}

Background: Surgeons' role in informed consent is crucial and should know the basic principle of informed consent in collecting and providing information to patients. Surgeons' attitudes toward informed consent depends on the knowledge they possess.

Objectives: Surgeons should become aware of the informed consent guidelines. New guidelines for consent have resulted in changes in health care environment that surgeons must adhere to. This study aims to highlight the way the surgeons in private hospitals view the informed consent for surgery processes.

Methods: This study is a cross-sectional survey that was conducted from January to June 2016 in two private hospitals. The sampling unit used in this survey was private hospitals in Kuwait. A custom designed questionnaire about informed consent for surgery was completed by surgeons working at private hospitals in Kuwait. The questionnaire was developed to examine the surgeons' attitudes towards informed consent. The participants, who were surgeons and working in the various surgical specialties in the two hospitals, were made aware that the emphasis was on the verbal or written information about the operation they provide their patients with and not merely about the signing of the consent form which could take place at the same time or later. They were asked to respond to each question by Yes (agreeing) or No (disagreeing) or Unsure. The responses of the surgeons to each statement were calculated, using Statistical analysis SPSS version 21.

Results: A high proportion $98.1 \%$ of private surgeons considered informed consent routinely achieved in their current practice. They thought that all surgeons should receive formal training on informed consent $81.6 \%$. They have been received formal training on informed consent $76.7 \%$. On the other hand, private surgeons thought that written information leaflets should be provided for patients during informed consent $46.6 \%$. However, only $30.1 \%$ of private surgeons provide their patients with leaflets during informed consent. A high proportion of private surgeons $86.4 \%$ thought that the main purpose of informed consent is to provide the surgeon with greater protection against litigation. Furthermore, $95.1 \%$ of private surgeons thought that the main purpose of informed consent is to respect the patient's right of autonomy. The majority of private surgeons $94.3 \%$ thought that the main purpose of informed consent is to improve the doctor patient relationship, and $83.5 \%$ of private thought that the main purpose of informed consent is to improve the patient's compliance with medical care. On other hand, lower percentages $42.7 \%$ of private surgeons thought that informed consent may be unnecessary because most patients depend on their doctor to make the decision for them, and $62.1 \%$ of private surgeons thought that the doctor who is going to perform the operation, who should do the informed consent. Also, more private surgeons thought that the patients age, complexity and duration of surgery, gender, the patient social class, the timing of surgery, and the need for referral to another doctor or hospital affects the amount of information given during informed consent.

Conclusion: Surgeons in private should be more aware of the informed consent guidelines and they should adhere to them. Training on informed consent in both hospitals are recommended, and to provide more leaflet for patient during informed consent is required and important.

Keywords: Informed consent, surgical risk, private.

Correspondence to: Dr. Saadoun Al Azmi

Mobile: $+965-99656756$

E-mail: drsaadoun@yahoo.com; sf.alazmi@ paaet.edu.com

\section{INTRODUCTION}

$\mathbf{I}_{\mathrm{n}}^{\mathrm{n}}$ nformed consent which is routinely provided to surgical patients in private hospitals is an important source of information to help patient make informed decision about their treatment (1). Informed Consent serves to recognize and respect a patient's best concern by giving each patient to decide autonomously what his best interests are in light of planned procedure $(2,3)$. Informed consent is primary part of every surgeon's daily practice. Surgical patients need the most information and direction before medical intervention because many surgical procedures are complicated and the attendant risks and benefits are unfamiliar to patients. The consent form should explain and describe the nature and 
type of treatment also include problem alternative treatment risk and side effects of treatments and consequences of no treatments should also stated. The need for surgeons to reevaluate their own understanding of the components of informed consent is critical in such process. Studies indicated that Doctors' attitude toward informed consent depends on their knowledge they possess (4). Therefore, some surgeon's may lake a proper understanding of how to engage patient in this important process (5). Consent is ethical and legal requirement. It is an authorization that must be obtained from patient before any procedures is carried out in medical practice and necessary for legal protection against malpractice claims (6). Ministerial decree number No. 307/2015 of the ministry of health in Kuwait stated that doctors should provide all information including possible risks (7) In some research studies designed to assesses understanding of patients' about informed consent have shown that most patients are poorly informed, and informed consent seen as nothing more than a patient's signature rather than mutual understanding, and serious decision making process between patients and surgeon (8). In addition, studies in which patients had consented to surgical interventions found significant deficiencies in key area such as understanding of option, potential outcomes and morbidity and mortality risks. (9)

Research studies also suggested that many patients who gave written consent reported they do not read and understand the consent. (10) This study is important because few studies were conducted in the field of informed consent process at private sector in the state of Kuwait. Therefore, the objectives of this study are to assess the attitudes of private surgeons working in private hospitals towards informed consent and to highlight the way the private surgeons view the informed consent for surgery processes.

\section{SUBJECTS AND METHODS}

This study is a cross-sectional survey that was conducted from January to June 2016 in two private hospitals. The sampling unit used in this survey was two private hospitals in Kuwait. This is a one-stage stratified random sample (SRS) at hospital level; two hospitals were selected at random among the 11 private hospitals in Kuwait (Hadi and Dar Alshifa hospitals). Then took all surgeon at the physicians' level. One hundred twenty questionnaires were distributed according to the total number of surgeons in the two selected hospitals. A custom designed questionnaire about informed consent for surgery derived from different published studies dealing with the same topic as well as from our own experience was used in this study (11).

The questionnaire was completed by the surgeons working at the two private hospitals. The questionnaire made up of 30 questions that developed to examine the surgeons' attitudes towards informed consent. The participants, who were surgeons and working in the various surgical specialties with different professionals' titles (consultants, senior specialist, specialist, senior registrar, registrar, assistant registrar) in the two hospitals were asked to respond to each question by Yes (agreeing) or No (disagreeing) or Unsure. The responses of the surgeons to each statement were calculated using descriptive statistics in which, description of qualitative variables was performed by frequency tables and quantitative variables by calculation of mean \pm standard deviation. Statistical analysis was done using SPSS version 21.

\section{RESULTS}

Of the 120 questionnaires distributed (each hospital 60) which represent almost the total number of surgeons' working in studied hospitals, 103 were returned; with a response rate of $(85.8 \%)$. Of those $55(53.4 \%)$ were Hadi hospital surgeons and,48(46.6\%) were Dar Elshifa hospital surgeons. Most of surgeons were males 71(68.9\%) and 32 (31.1 $\%)$ were females. $(12.6 \%)$ of them were single, $(58.3 \%)$ were married, $(4.9 \%)$ were divorced and, (5.8\%) were widow. The average age value was $46.77 \pm 10.74$. Surgeons were having different professional categories: (5.8\%) Assistant Registrar, (26.2 \%) Registrar, (6.8\%) Senior Registrar, (16.5\%) Specialist, (11.7\%) Senior Specialist, (32.0\%) Consultant and one missing. Also, they work 
in different specialties, (21.4) \% were General Surgeon, $\quad(11.7 \%) \quad$ ENT, $\quad(7.8 \%)$ Ophthalmologist, (15.5\%) Orthopedic, (6.8\%) Gastroenterology, (19.4\%) Obstruction \& Gynecologist, (2.9\%) Chest Surgeon, (4.9\%) Maxillofacial, (4.9\%) Plastic Surgeon, and (4.9\%) Others Table 1.

Table 2: reveals that responses of the private surgeons to the general informed consent questions. High proportion of private surgeons $(98.1 \%)$ considered informed consent routinely achieved in their current practice. About $81.6 \%$ of private surgeons thought that all doctors should receive formal training on informed consent. Moreover, $76.7 \%$ of private surgeons have been received formal training on informed consent. On the other hand, $46.6 \%$ of private surgeons thought that written information leaflets should be provided for patients during informed consent. Only $30.1 \%$ of private surgeons mentioned that they provide their patients with leaflets during informed consent.

Table 3: Illustrates responses of private surgeons to questions related to the main purpose of informed consent. About $85.4 \%$ of private surgeons thought that the main purpose of informed consent is to ensure that the patient has been informed of all potential complications. On the other hand, a high proportion of private surgeon $(86.4 \%)$ thought that the main purpose of informed consent is to provide the surgeon with greater protection against litigation. Similarly, $95.1 \%$ of private surgeons thought that the main purpose of informed consent is to respect the patient's right of autonomy. The majority of private surgeons $(94.2 \%)$ in both hospitals thought that the main purpose of informed consent is to improve the doctor patient relationship and $83.5 \%$ of private surgeons thought that the main purpose of informed consent is to improve the patient's compliance with medical care.

Table 4: Shows the responses of the private surgeons to questions on why informed consent may be unnecessary. Lower percentages in both hospitals thought that informed consent may be unnecessary because most patients depend on their doctor to make the decision for them $(42.7 \%)$ and
$(48.5 \%)$ of private surgeons thought that informed consent may be unnecessary because disclosing information to patients about potentially harmful risks may be worrying for them. On the other hand, 58.3\% of private surgeons thought that informed consent may be unnecessary because disclosing information about potentially harmful risks may dissuade patients from undergoing the operation. Moreover $(30.1 \%)$ of private surgeons thought that informed consent may be unnecessary because most patients do not usually remember all the information given to them.

Table 5: When surgeons were asked about who should do the informed consent and what should be disclosed during the process? $62.1 \%$ of private surgeons thought that the doctor who is going to perform the operation should do the informed consent. While, $58.3 \%$ of private surgeons thought that the responsible consultant should do the informed consent. Moreover, $45.6 \%$ of private surgeons reported that a junior doctor who is not going to perform the operation should do the informed consent.

On the other hand, (70.9\%) of private surgeons thought that they should disclose the possibility of death if present and, (981\%) of private surgeons thought that they should disclose all major risks with incidence more than $1 \%$. Furthermore $(73.8 \%)$ of private surgeons thought that they should disclose all minor risks with incidence more than 5\%.

Table 6: Responses of the private surgeons to questions on factors affecting the information given during informed consent. Majority of private surgeons $(85.4 \%)$ thought that the patients age affects the type of information given during informed consent and, (79.6\%) of private surgeons thought that the patients gender affects the amount of information given during informed consent. On the other hand, $(58.3 \%)$ of private surgeons thought that the patients level of education affects the of information given during informed consent. Furthermore (78.6\%) of private surgeons thought that the patients social class affects the type of information given during informed consent and (57.3\%) of private surgeons thought that the patients 
source of funding for treatment affects the type of information given during informed consent.

About (44\%) of the studied private surgeons thought that the patient's clinical presentation whether emergency or elective affects the information given during informed consent. While $(80.6 \%)$ of private surgeons thought that the Complexity and duration of surgery affect the information given during informed consent and $(76.7 \%)$ of private surgeons thought that the timing of surgery affects the information given during informed consent. Only (19.4\%) of private surgeons thought that how busy you are at the time affects the information given during informed consent and $(74.8 \%)$ of private surgeons thought that the need for referral to another doctor or hospital affects the amount of information given during informed consent.

Table 1: Sociodemographic Variables of private sector

\begin{tabular}{|c|c|c|c|}
\hline Variable & & $\mathrm{n}$ & $\%$ \\
\hline \multirow[t]{2}{*}{ Hospitals } & Dar Elshifa & 48 & 46.6 \\
\hline & Hadi & 55 & 53.4 \\
\hline \multirow[t]{2}{*}{ Gender } & Males & 71 & 68.9 \\
\hline & Females & 32 & 31.1 \\
\hline Age ( Years) & $\left(\mathrm{X}_{ \pm} \mathrm{SD}\right)$ & & $(46.77 \pm 10.74)$ \\
\hline \multirow[t]{5}{*}{ Marital status } & Single & 13 & 12.6 \\
\hline & Married & 60 & 58.3 \\
\hline & Divorced & 5 & 4.9 \\
\hline & Widow & 6 & 5.8 \\
\hline & Missing & 19 & 18.4 \\
\hline \multicolumn{4}{|l|}{ Profession } \\
\hline & Assistant Registrar & 6 & 5.8 \\
\hline & Registrar & 27 & 26.2 \\
\hline & Senior Registrar & 7 & 6.8 \\
\hline & Specialist & 17 & 16.5 \\
\hline & Senior Specialist & 12 & 11.7 \\
\hline & Consultant & 33 & 32.0 \\
\hline & Missing & 1 & 1.0 \\
\hline \multirow[t]{10}{*}{ Specialty } & General surgery & 22 & 21.4 \\
\hline & ENT & 12 & 11.7 \\
\hline & Ophthalmology & 8 & 7.8 \\
\hline & Orthopedic & 16 & 15.5 \\
\hline & Gastroenterology & 7 & 6.8 \\
\hline & $\begin{array}{l}\text { Obstruction \& } \\
\text { Gynecologist }\end{array}$ & 20 & 19.4 \\
\hline & Chest surgeon & 3 & 2.9 \\
\hline & Maxillofacial & 5 & 4.9 \\
\hline & Plastic surgeon & 5 & 4.9 \\
\hline & Others & 5 & 4.9 \\
\hline Years of experience( Years) & $\left(\mathrm{X}_{ \pm} \mathrm{SD}\right)$ & & $(20.79 \pm 10.72)$ \\
\hline
\end{tabular}


Table 2: Responses of the private surgeons to the general informed consent questions

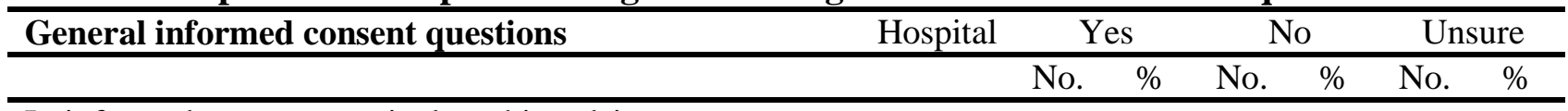

Is informed consent routinely achieved in your current

practice

\begin{tabular}{lllllll} 
Private & 101 & 98.1 & 0 & 0.0 & 2 & 1.9 \\
\hline
\end{tabular}

Do you think that all doctors should receive formal

training on informed consent?

\begin{tabular}{llllllll}
\hline & Private & 84 & 81.6 & 4 & 3.9 & 15 & 14.6 \\
\hline $\begin{array}{l}\text { Have you received any formal training on informed } \\
\text { consent }\end{array}$ & & & & & & & \\
\hline & Private & 79 & 76.7 & 23 & 22.3 & 1 & 1.0 \\
\hline
\end{tabular}

Should written information leaflets be provided for

patients during informed consent

Do you provide your patients with leaflets during

informed consent

\begin{tabular}{lllllll} 
Private & 48 & 46.6 & 7 & 6.8 & 48 & 46.6 \\
\hline
\end{tabular}

\begin{tabular}{|c|c|c|c|c|c|c|}
\hline Private & 31 & 30.1 & 31 & 30.1 & 4 & 308 \\
\hline
\end{tabular}

Table 3: Responses of the private surgeons to questions related to the main purpose of informed consent

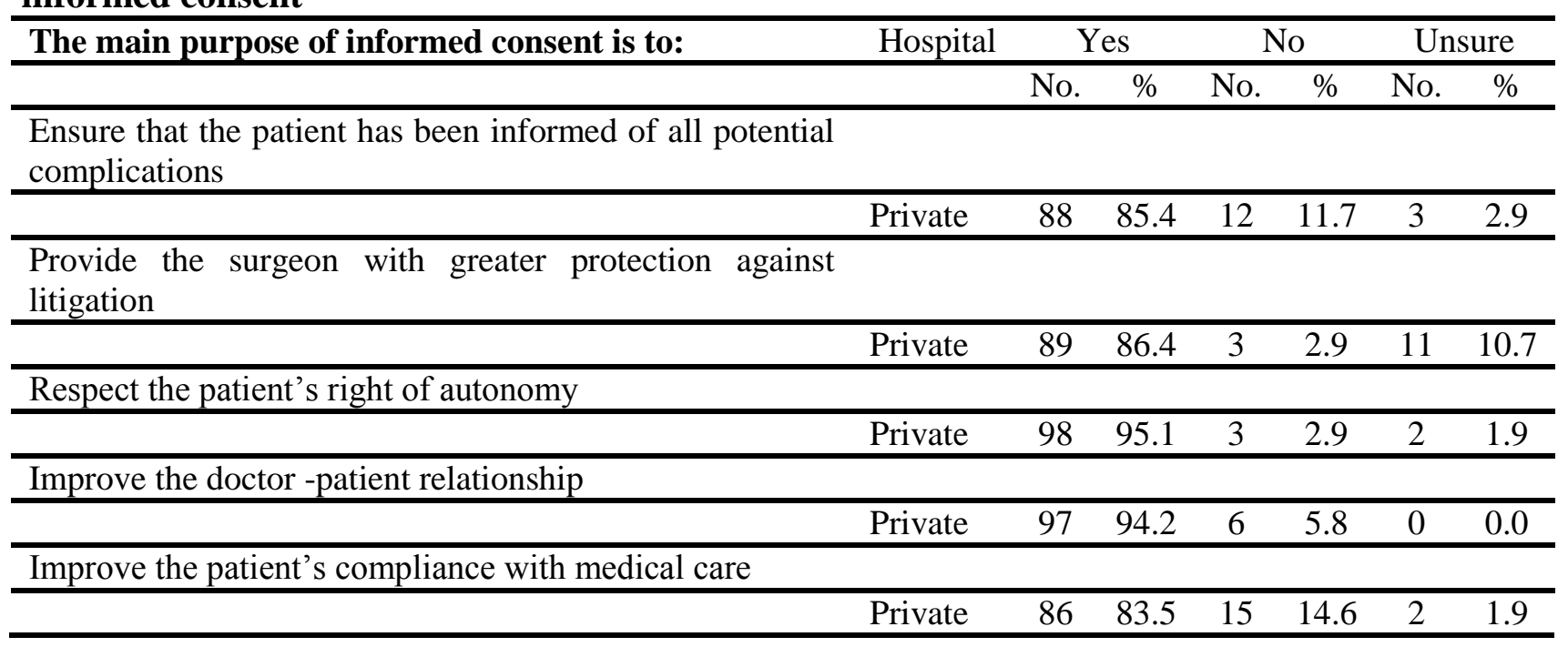

Table 4: Responses of the private surgeons to questions on why informed consent may be unnecessary

\begin{tabular}{|c|c|c|c|c|c|c|c|}
\hline \multirow[t]{2}{*}{ Informed consent is unnecessary because: } & \multirow[t]{2}{*}{ Hospital } & \multicolumn{2}{|c|}{ Yes } & \multicolumn{2}{|c|}{ No } & \multicolumn{2}{|c|}{ Unsure } \\
\hline & & No. & $\%$ & No. & $\%$ & No. & $\%$ \\
\hline \multicolumn{8}{|l|}{$\begin{array}{l}\text { Most patients depend on their doctor to make the decision for } \\
\text { them }\end{array}$} \\
\hline & Private & 44 & 42.7 & 56 & 54.4 & 3 & 2.9 \\
\hline \multicolumn{8}{|l|}{$\begin{array}{l}\text { Disclosing information to patients about potentially harmful risks } \\
\text { may be worrying for them }\end{array}$} \\
\hline & Private & 50 & 48.5 & 42 & 40.8 & 11 & 10.7 \\
\hline \multicolumn{8}{|l|}{$\begin{array}{l}\text { Disclosing information about potentially harmful risks may } \\
\text { dissuade patients from undergoing the operation }\end{array}$} \\
\hline & Private & 60 & 58.3 & 40 & 38.8 & 3 & 2.9 \\
\hline \multicolumn{8}{|l|}{$\begin{array}{l}\text { Most patients do not usually remember all the information given } \\
\text { to them }\end{array}$} \\
\hline & Private & 31 & 30.1 & 33 & 32.0 & 39 & 37.9 \\
\hline Saadoun F.\& Bashair A. & & & & & & & 96- \\
\hline
\end{tabular}


Table 5: Responses of the private surgeons to questions on who should do the informed consent and what should be disclosed during the process

Questions related to who should do the informed consent and what should you disclose during the process?

\begin{tabular}{|c|c|c|c|}
\hline Hospital & Yes & No & Unsure \\
\hline
\end{tabular}

The doctor who is going to perform the operation

\begin{tabular}{lllllll} 
Private & 64 & 62.1 & 38 & 36.9 & 1 & 1.0 \\
\hline
\end{tabular}

The responsible consultant

\begin{tabular}{lllllll} 
Private & 60 & 58.3 & 42 & 40.8 & 1 & 1.0 \\
\hline
\end{tabular}

A junior doctor who is not going to perform the operation

\begin{tabular}{llrrrrrr}
\hline operation & Private & 47 & 45.6 & 50 & 48.5 & 6 & 5.8 \\
\hline Should disclose the possibility of death if present & & & & & & \\
\hline & Private & 73 & 70.9 & 10 & 9.7 & 20 & 19.4 \\
\hline Should disclose all major risks with incidence more & & & & & & &
\end{tabular}

Should disclose all major risks with incidence more than $1 \%$

\begin{tabular}{lllllll} 
Private & 101 & 98.1 & 1 & 1.0 & 1 & 1.0 \\
\hline
\end{tabular}

Should disclose all minor risks with incidence more than $5 \%$

\begin{tabular}{lllllll} 
Private & 76 & 73.8 & 16 & 15.5 & 11 & 10.7 \\
\hline
\end{tabular}

Table 6: Responses of the private surgeons to questions on what affect the amount of information given during informed consent

\begin{tabular}{|c|c|c|c|c|c|c|c|}
\hline \multirow[t]{2}{*}{$\begin{array}{l}\text { Questions related to factors affecting the amount of } \\
\text { information given to patients during informed } \\
\text { consent }\end{array}$} & \multirow[t]{2}{*}{ Hospital } & \multicolumn{2}{|c|}{ Yes } & \multicolumn{2}{|c|}{ No } & \multicolumn{2}{|c|}{ Unsure } \\
\hline & & No. & $\%$ & No. & $\%$ & No. & $\%$ \\
\hline \multicolumn{8}{|l|}{ The patients age } \\
\hline & Private & 88 & 85.4 & 14 & 13.6 & 1 & 1.0 \\
\hline \multicolumn{8}{|l|}{ The patients gender } \\
\hline & Private & 82 & 79.6 & 20 & 19.4 & 1 & 1.0 \\
\hline \multicolumn{8}{|l|}{ The patients level of education } \\
\hline & Private & 60 & 58.3 & 42 & 40.8 & 1 & 1.0 \\
\hline \multicolumn{8}{|l|}{ The patients social class } \\
\hline & Private & 81 & 78.6 & 20 & 19.4 & 2 & 1.9 \\
\hline \multicolumn{8}{|l|}{ The patients source of funding for treatment } \\
\hline & Private & 59 & 57.3 & 41 & 39.8 & 3 & 2.9 \\
\hline \multicolumn{8}{|l|}{$\begin{array}{l}\text { The patient's clinical presentation whether } \\
\text { emergency or elective }\end{array}$} \\
\hline & Private & 46 & 44.7 & 56 & 54.4 & 1 & 1.0 \\
\hline \multicolumn{8}{|l|}{ The Complexity and duration of surgery } \\
\hline & Private & 83 & 80.6 & 20 & 19.4 & 0 & 0.0 \\
\hline \multicolumn{8}{|l|}{ The timing of surgery } \\
\hline & Private & 79 & 76.7 & 22 & 21.4 & 2 & 1.9 \\
\hline \multicolumn{8}{|l|}{ How busy you are at the time } \\
\hline & Private & 20 & 19.4 & 43 & 41.7 & 40 & 38.8 \\
\hline \multicolumn{8}{|l|}{ The need for referral to another doctor or hospital } \\
\hline & Private & 77 & 74.8 & 15 & 14.6 & 11 & 10.7 \\
\hline
\end{tabular}




\section{DISCUSSION}

The finding of this research study with respect to the awareness level and adherence to guidelines of informed consent by doctors(surgeons) is not clear in both hospitals. The responding surgeons could be considered as a fair representative of surgeons practicing in such hospitals type because they were chosen randomly, of varied level of seniority, of broad spectrum of surgical specialties and different training background and, also that the attitude of surgeons practicing in other hospitals is unlikely to differ from those chosen randomly. It also can be assumed that the surgeons' responses to the questions were influenced by codes of practice in their hospitals and that the findings of this study represent the attitudes of surgeons working in such types of hospital.

Most private surgeons stated that informed consent was routinely achieved in their practice; They also believe that all doctors should receive formal training on informed consent. In addition, they agreed that written information (leaflets) should be given to patients during informed consent; however, $(30.1 \%)$ private surgeons indicated that they were doing that already. This could reflect the practice in private hospitals, in which most surgeons do not give always their patients leaflets during informed consent or sometimes leaflets may be unavailable. Written information is useful for patients. Most participants believe that the consent process should include an explanation of what the procedure entails and that one of the main purposes of the consent process was to respect patients' right to autonomy. Our sample of participants however had a minority of respondents with an apparently paternalistic attitude towards the consent process. Several surgeons believed that the consent process was inappropriate as information disclosed may be confusing to patients or may dissuade them from undergoing the procedure. This goes against the current guidelines and legal position that the patient should be told what a reasonable patient in the patient's position would want to know (12). $85.4 \%$ of private surgeons agreed that the main purposes of informed consent were to ensure that the patient is informed of all potential complications and also to provide the surgeon with greater protection against litigation $(86.4 \%)$. However, more private surgeons believe that the main purpose of informed consent also includes improving the doctor-patient relationship $(94.2 \%)$ and improving the patients' compliance with medical care $(83.5 \%)$. Such findings mean that surgeons in both hospitals considered informed consent as a legal and ethical obligation. Studies revealed that prior information about a procedure and its risks improves patients' compliance and postprocedure progress, in addition to reducing post-operative medication use (13). However, some patients may not want to know such details (14). This study showed that Private surgeons disagreed with informed consent being done by a junior doctor who was not going to perform the operation $(45.6 \%)$. This can be justified as a junior doctor may not be able to provide all the information necessary to patient. In addition, more private surgeons believed that informed consent should be done by the consultant or by the doctor who was going to perform the operation. This is consistent with the widely-accepted policy that the responsibility of obtaining informed consent for an operation ultimately lies with the surgeon carrying out such operation (15).

The participating surgeons' opinion with respect to levels of risk disclosure they went on line with the need to disclose to patients the risk of death if present $(70.9 \%)$ and to disclose all major risks $(98.1 \%)$ with incidence $>1 \%$ and all minor risks $(73.8 \%)$ with incidence $>5 \%(16)$. This study revealed that information with respect to informed consent was influenced by several factors some of them are patient-related and others are not. These included; the patient's age, gender, level of education, social class, source of funding for treatment, clinical presentation whether emergency or elective, complexity and duration of surgery, timing of surgery, how busy the surgeons' available time and the need for referral to another doctor or hospital. This observation is another indication of paternalistic attitude by the private surgeons. Such observations by private surgeons are 
unjustifiable, although the variation in the levels of education, socio-economic status of the private patients are related. However, patients are varied in the amount and type of information they want to remember and understand (13).

\section{CONCLUSION}

This study concludes that private surgeons tend to look at informed consent as not only an ethical and legal obligation, but also of benefit to patients. However, surgeons should become aware of the informed consent guidelines that introduce by Ministry of Health. In addition, the introduction of formal training on informed consent in private hospitals are recommended and for making written information(leaflets) more widely available is required.

\section{ACKNOWLEDGMENTS}

The authors would like to thank all private surgeons who participants for their participation and kind cooperation throughout the study.

\section{REFERENCES}

1. Andre J. Bioethics as practice. Chaepel Hill: University of North Carolina Press; 2002.

2. Jafarey AM. Informed consent in research and clinical situations. J Pak Med Assoc. 2003 May;53(5):171e2.

3. Ryan C. Consenting adults. BMA News Rev; 1998:24e9.

4. Alphonsa B Fernandes, Seta D'Cunha, Sucharita Suresh. International Journal of Research Foundation of Hospital and Healthcare Administration, January-June 2014;2(1):25-30

5. Gupta, V. V., Bhat, N., Asawa, K., Tak, M., Bapat, S., \& Chaturvedi, P. (2015). Knowledge and Attitude Toward Informed Consent Among Private Dental Practitioners in
Bathinda City, Punjab, India. Osong Public Health and Research Perspectives, 6(2), 73-78.

6. Meisel A, Kuczewski M. Legal and ethical myths about informed

consent. Arch Intern Med 1996 Dec;156(22):2521e6.

7.Ministry of Health , Kuwait. Annual Group of the most important ministerial and administrative degree , Group 38, 2015.

8. Sinha, R. K., \& Irfan, H. (2016). Knowledge, Attitude and Practice of Informed Consent. Management in Health, 20(1).

9. Kalantri SP. Informed consent in public hospitals. Issues Med Ethics. 2000 Oct;8(4):116-7.

10. Akkad A, Jackson C, Kenyon S, DixonWoods M, Taub N, Habiba M. Informed consent for elective and emergency surgery: questionnaire study. BJOG: An International Journal of Obstetrics \& Gynaecology. 2004 Oct 1;111(10):1133-8.

11. Bakur A. Jamjoom, Aimun A.B. Jamjoom, Momen Sharab, Abdulhakim B. Jamjoom. Attitudes Towards Informed Consent: A Comparison between Surgeons Working in Saudi Arabia and the United KingdomOman Medical Journal (2011) Vol. 26, No. 1: 29-33.

12. Pearce $\mathrm{v}$ United Bristol Healthcare NHS Trust. 48 BMLR 118 (CA) 1998

13. Dawes PJ, Davison P. Informed consent: what do patients want to know? J Royal Soc. Med. 1994:87:149-52.

14. Akkad A, Jackson C, Kenyon S, DixonWoods M, Taub M, Habiba M. Patients' perceptions of written consent: questionnaire study. Br Med J. 2006; 333:528.

15. UK Department of Health's Good Practice in consent implementation guide: consent to examination or treatment. 2001.

16. Calman KC. Communication of risk: choice, consent, and trust. Lancet $2002 \mathrm{Jul}$; 360(9327):166-168. 